\title{
Intelligent Visualization of Anchor Drill Based on PLC, Interface and Frequency Converter
}

\author{
Gai-Lian Zhang ${ }^{1, a}$ \\ ${ }^{1}$ School of Applied Technology, Xi'an International University, Xi'an, Shaanxi, PR. China 710077 \\ ${ }^{a}$ email,
}

Keywords: Anchor Drilling Rig; PLC; Man-Machine Interface; Frequency Converter

\begin{abstract}
Aiming at the problems existing in the bolt drilling rig, an intelligent visualization scheme based on PLC, interface and frequency converter was used to reform the control system of a certain type of bolt rig. Through analyzing the control principle of the system, the PLC terminal wiring diagram is designed, the flow chart of the control system is given, and finally the PLC program and the man-machine interface design are finished. The experimental results show that the modified control system has the advantages of simple circuit, good reliability, high efficiency and easy maintenance.

The rock drill rig is an important equipment in the drilling construction. Its quality has a great influence on the speed of the support . In different projects, types of anchor drills are generally selected, among which the most Common is the airborne hydraulic bolt rig . However, the traditional hydraulic bolt rig has many shortcomings, for example: its impact period and energy can not be automatically adjusted, only can rely on manual experience adjustment, poor adaptability to different geological conditions. In addition, the rig is not high degree of automation, common hydraulic anchor drill through the relay - contactors and other logic to control, not only the complexity of the circuit, and poor operational reliability, post-maintenance work difficult . In view of the above question, this article selects the PLC, the frequency changer, the touch screen to carry on the transformation to the electric power control system of the bolt drilling rig.
\end{abstract}

\section{Control System Design}

The main components of the system include PLC, V / F inverter, HMI, flow sensor, pressure sensor, speed sensor and displacement sensor, hydraulic pressure control system, Motor, rotor pump, hydraulic rotary unit, hydraulic impact unit, energy storage tank and hydraulic impactor and other components.

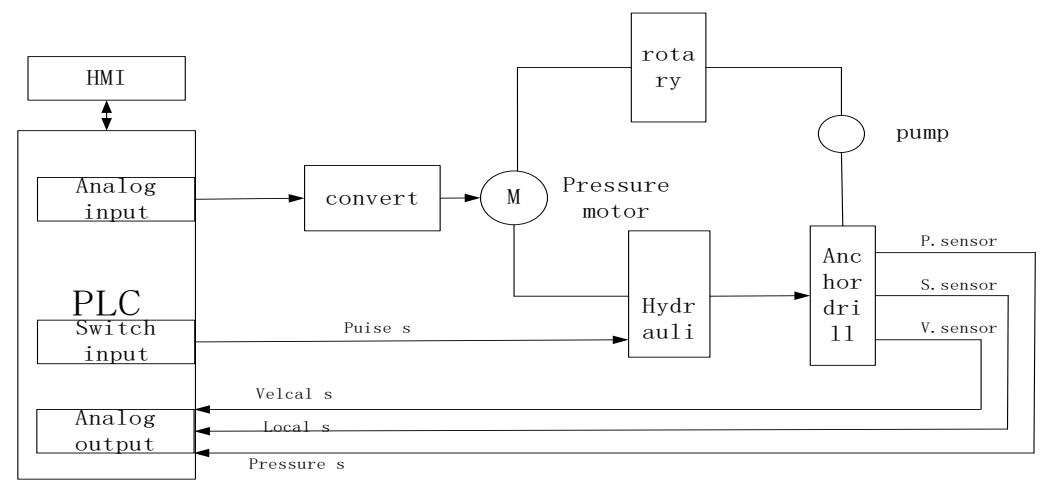

Figure1

When the system works, the adjustable speed of the pump to the hydraulic shock unit and hydraulic rotary unit to provide a certain pressure of hydraulic oil. The rotary hydraulic unit through four method solenoid valve control is reversed when the solenoid switch on the solenoid valve ,on the left side of the rig, the forward rotation, when the solenoid switch on the solenoid valve on the 
right side of the rig, reverse rotation, when both ends of the electromagnetic valve electromagnet are not connected, the pressure oil directly back to the tank, drill does not rotate. The hydraulic shock unit through a two position four way solenoid valve to control the working state, when the electromagnet is turned on, the driving hammer hydraulic oil drilling, at this point, we can adjust the relief valve to control the impact force. The selection of hydraulic oil flow sensor on the quantitative pump output is detected, the anchor rig is installed on the speed sensor, displacement sensor and pressure sensor to detect the piston velocity, drilling work in the process of moving distance and the pressure of hydraulic oil. All these will be measured by the sensor signal (usually pressure signal) for A/D conversion into a digital signal PLC can read, PLC processing of these signals (the actual signal values are compared with the reference value output to the PID controller), the result of an operation is a digital quantity, must after D/A conversion can be used to control the frequency converter, the hydraulic pump speed analog signals corresponding to different different, also correspond to different flow of hydraulic oil, so as to control the jumbolter continuous and real-time. The impact of high frequency when the hydraulic impactor, the piston stroke of the hydraulic impactor is short, the condition of the corresponding rock hardness is not high, the jumbolter should work in a smaller impact energy under the high hardness of rock; instead the jumbolter at this time should work in the larger impact energy under . The human-computer interaction interface can monitor the parameters, states and the alarm information of the bolt drilling machine, which greatly increases the convenience of using. Through the monitoring of operating parameters, using PLC to achieve closed-loop control, frequency, displacement and energy of drill output continuously adjusted, so as to enhance the real-time and adaptability of roofbolter.

\section{Hardware Design}

PLC Selection and Port Design. Under the condition that the mechanical structure of the anchor drill rig and the main circuit of the circuit are unchanged, the control system is reformed. The valve switching to replace the electromagnetic switch, increasing the sensor, including: the impact of component displacement sensor, detection speed sensor and a pressure sensor, and the hydraulic pump flow sensor. The input signal of PLC is divided into two kinds, the switch signals and analog signals, switch signal input system start / stop signal, tank level signal, hydraulic oil temperature limit signal; switch signal output of the electromagnetic valve position signal, motor start / stop signal. The input analog signal has the pressure, the speed, the displacement signal and the hydraulic oil flow signal, and the output of the analog signal has the frequency converter control signal. Through the above on the input and output points of the statistics, considering the requirements of the control performance, here is the SIEMENS S7-200 series PLC, AC/RELAY (16DI specific model CPU224 /10DO), because the model PLC no analog input and output function, therefore must develop a EM235 analog module, it has 4 analog inputs and 4 analog output . PLC terminal diagram shown in figure 2. 


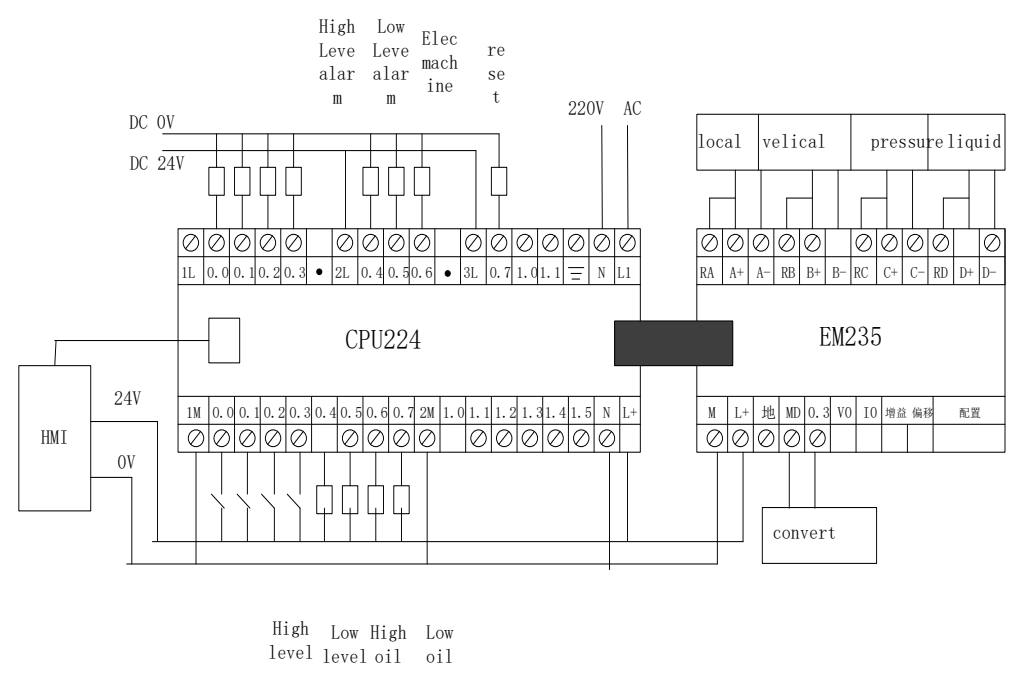

figure2

The address assignment of the PLC input port and the output port is shown in Table 1 and table 2.

Table 1

\begin{tabular}{lll}
\hline function & element & address \\
\hline Start switch & SB1 & I0.0 \\
Stop switch & SB2 & I0.1 \\
auto mode switch & SA1 & I0.2 \\
Manual mode switch & SA2 & I0.3 \\
Hydraulic oil level upper limit switch & BG1 & I0.4 \\
Hydraulic oil level height limit switch & BG2 & I0.5 \\
$\begin{array}{l}\text { Hydraulic oil temperature upper limit } \\
\text { switch }\end{array}$ & BT1 & I0.6 \\
Hydraulic oil temperature height limit & BT2 & \\
switch & & I0.7 \\
Impact component displacement signal & AS & \\
impact & & AIW0 \\
Impact component speed signal impact & AV & \\
Impact component press signal impact & AP & AIW2 \\
Hydraulic oil flow signal & AQ & AIW4 \\
\hline
\end{tabular}


Table 2

\begin{tabular}{lll}
\hline function & element & address \\
\hline $\begin{array}{l}\text { Four position three way solenoid valve } \\
\text { left signal }\end{array}$ & YA1 & Q0.0 \\
& & \\
& & \\
$\begin{array}{l}\text { Four position three way solenoid valve } \\
\text { right signal }\end{array}$ & YA2 & Q0.1 \\
two position four way solenoid valve left & YA3 & Q0.2 \\
$\begin{array}{l}\text { signal } \\
\text { two position four way solenoid valve }\end{array}$ & YA4 & \\
$\begin{array}{l}\text { right signal } \\
\text { Hydraulic oil height limit alarm }\end{array}$ & YA5 & \\
$\begin{array}{l}\text { Hydraulic oil temperate limit alarm } \\
\text { Motor running }\end{array}$ & YA6 & Q0.4 \\
Frequency converter control signal & M & Q0.5 \\
\hline
\end{tabular}

\section{Type Selection of Frequency Converter}

Through the calculation of the power to the hydraulic system, ultimately determine the power required for the $50 \mathrm{KW}$, so here is the choice of the $55 \mathrm{KW}$ Snyder frequency converter, the model is V8T455ROG. This inverter uses the integration of the body design, has the advantages of easy debugging, high efficiency and stability, the internal integration of the simple PLC, with multiple input and output ports, and has the PID control function.

Sensor Selection. Through the analysis of the system, the selection of the sensor is as follows:

1) displacement sensor: NOVO TEKLINK;

2) speed sensing: Trans-Tek;

3) pressure sensor: GEMSP71200;

4) flow sensor: HYDEVS3100EVS3100-H-3015-300 flow sensor.

Type Selection of Interface. The interface using touch screen from Delta company, the model for the DOP-B10S411, users can not only monitor the operation state on the touch screen, you can also modify the operating parameters. By programming software DOPSoft, developers can be use the computer on the touch screen configuration, including the modification of the monitor screen, the PLC internal register values and the state to modify the communication address set. Write the completed program through the download line to download the touch screen, PLC and touch screen through a dedicated serial communication.

\section{Software Design}

Flow Chart Design of Control System. Flow chart of control system is shown in Figure 3, the system first initialized, and then the temperature of hydraulic oil and hydraulic oil level to determine if there is alarm signal is terminated, otherwise the program continued execution program reads the parameters set from the touch screen finally, by judging the work mode of system, which performs automatic program and manual procedures. 


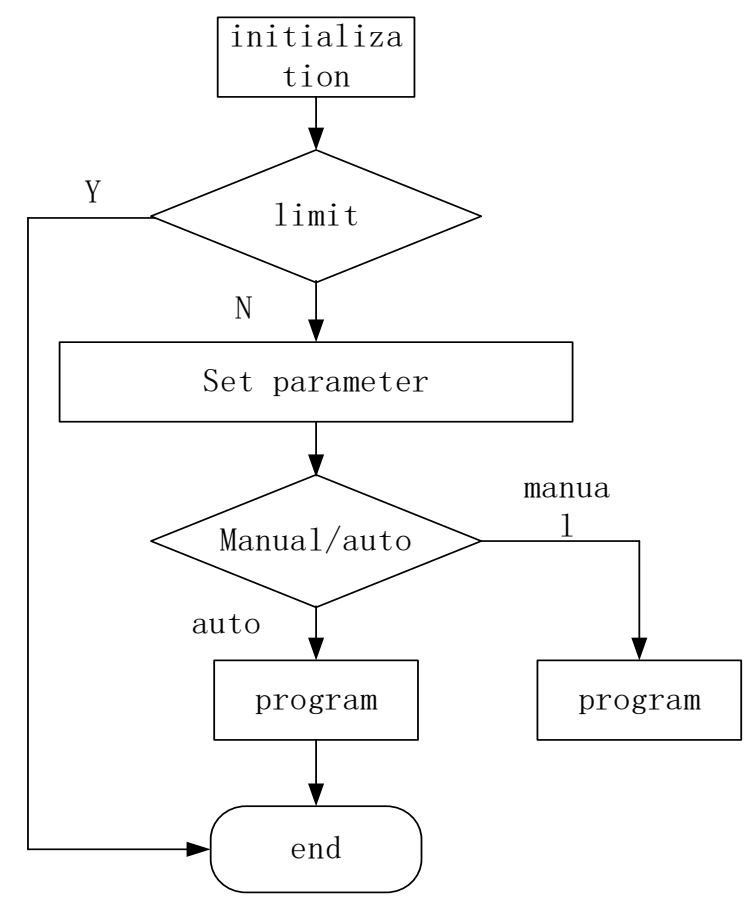

Figure3

PLC Program Design. PLC programming is the most important part of the whole control system, according to the control requirements of the anchor rig, select the appropriate mode of operation and control parameters, in order to cope with different conditions. Through the analysis of the working process of the bolt drilling machine, combined with the input and output address table of PLC, the control program is written by ladder diagram. The program generally includes two parts: main program and sub program. System initialization, touch screen parameters of the reading, manual and automatic mode of judgment, etc. are in the main program to achieve. The initialization of the system includes the initial speed of the transducer, the setting of the communication parameters and the control parameters of the PID operation. After the initialization of the system to enter the alarm signal, if no alarm signal is entered into the automatic / manual mode selection. The subroutine mainly includes 4 analog signal acquisition, analysis and calculation, different interrupt service routines for each signal of the PID loop operation. Among them, the PID loop through the real-time signal acquisition of subroutine and the preset values are compared, combined with the initialization of the proportional integral and differential time constant is calculated to control the amount of control after $\mathrm{D} \backslash \mathrm{A}$ conversion by the extension module EM235 output.

Man-Machine Interface Program Design. In the special configuration software DOP-B10S411 to develop the DOPSoft man-machine interface, touch screen and PLC communication through the DOPB-S7200 professional communication line to achieve. The monitor interface of the main menu as shown in 4 (other interface does not introduce). 


\section{Hydraulic rock drill rig control system}

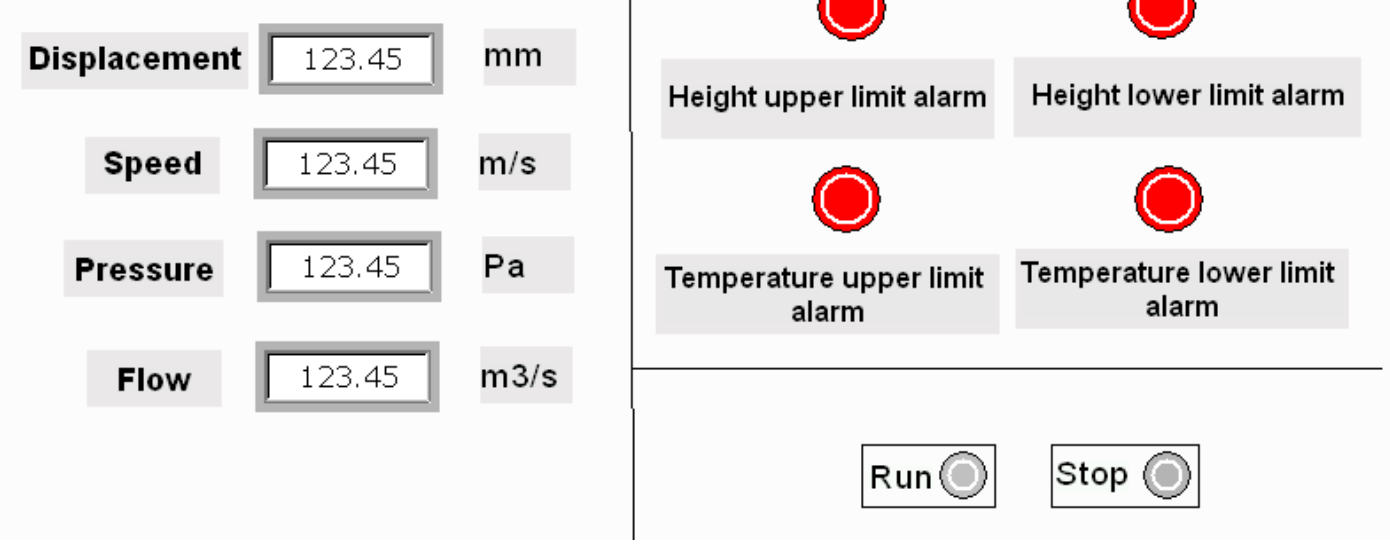

Figure4

\section{Conclusion}

This paper introduces the anchor rig PLC, man-machine interface, inverter control system based on the system with PLC as the main controller, sensor input PLC to jumbolter operating parameters, through signal processing and closed-loop control, the controller output signal in real-time simulation of the hydraulic pump of stepless speed regulation, so as to meet the performance requirements under various conditions. The use of human-computer interaction interface makes the monitoring mode more intuitive, simplifies the control mode, and provides a great convenience for the subsequent maintenance. Through experiments, the results show that the control system has excellent performance, which can provide reference for similar system design.

\section{Acknowledgements:}

This work was financially supported by Shaanxi Provincial Education Commission (ProgramNo.16JK2174)

\section{References}

[1] He Lijun. A new multi-functional full hydraulic jumbolter research of key technology of [D]. China University of Geosciences, 2010

[2] Xu Suogeng. Current situation and development trend of anchor drilling machine at home and abroad [J]. coal mining machinery, 2007,11:1-3.

[3] Wang Xiaoyu. Design of variable frequency constant pressure water supply system based on PLC and J]. (HMI manufacturing automation, 2011, 33 (5): 119 - 122

[4] Chen Ling, Shi Feng, Yang Cunzhi. VVVF control based PLC control in hydraulic winch system in the application of J]. hydraulic and pneumatic, 2007 (11): 16 - 17

[5] SIEMENS S7-200 series PLC software, hardware manual M]. Liberal arts star. Research on Intelligent PID algorithm and its application in temperature control [D]. Donghua University, 2009 